\title{
A double-diffusive interface tank for dynamic-response studies
}

\author{
by Raymond W. Schmitt ${ }^{1,2}$, Robert C. Millard ${ }^{1}$, John M. Toole ${ }^{1}$ \\ and W. David Wellwood ${ }^{1}$
}

\begin{abstract}
A large tank capable of long-term maintenance of a sharp temperature-salinity interface has been developed and applied to measurements of the dynamical response of oceanographic sensors. A two-layer salt-stratified system is heated from below and cooled from above to provide two convectively mixed layers with a thin double-diffusive interface separating them. A temperature jump exceeding $10^{\circ} \mathrm{C}$ can be maintained over $1-2 \mathrm{~cm}$ (a vertical temperature gradient of order $10^{3 \circ} \mathrm{C} / \mathrm{m}$ ) for several weeks. A variable speed-lowering system allows testing of the dynamic response of conductivity and temperature sensors in full-size oceanographic instruments. An acoustic echo sounder and shadowgraph system provide nondisruptive monitoring of the interface and layer microstructure. Tests of several sensor systems show how data from the facility is used to determine sensor response times using several fitting techniques and the speed dependence of thermometer time constants is illustrated. The linearity of the conductivity-temperature relationship across the interface is proposed as a figure of merit for design of lag-correction filters to accurately match temperature and conductivity sensors for the computation of salinity. The effects of finite interface thickness, slow sensor sampling rates and the thermal mass of the conductivity cell are treated. Sensor response characterization is especially important for autonomous instruments where data processing and compression must be performed in-situ, but is also helpful in the development of new sensors and in assuring accurate salinity records from traditional wire-lowered and towed systems.
\end{abstract}

\section{Introduction}

The problem of matching the dynamic responses of temperature and conductivity probes for the accurate estimation of salinity dates back to the introduction of continuously recording profilers in the late 1960's (Fofonoff et al., 1974). Usually, the temperature probe is the slower responding sensor, resulting in an underestimate of the salinity when temperature is decreasing with time in the sensing volume, and an overestimate when temperature is increasing. The resultant "salinity spiking" at high gradient interfaces has long been the focus of many data analysis efforts (e.g., Fofonoff et al., 1974; Scarlet, 1975; Horne and Toole, 1980; Gregg et al., 1982; Gregg and Hess, 1985; Giles and McDougall,

1. Department of Physical Oceanography, Woods Hole Oceanographic Institution, Woods Hole, Massachusetts 02543 , U.S.A.

2. Corresponding author.email: rschmitt@whoi.edu 
1986; Ochoa, 1989). However, it is not often appreciated that the lag correction problem is equally important for salinity computation whenever the sensors are moving in a temperature gradient. Even if salinity spikes are filtered from the data, the estimated salinity will be incorrect without a proper match between the response times of the temperature and conductivity probes. With traditional wire-lowered CTD instruments, it is common to tune the lag-correction algorithm after the fact, since the complete data time-series from all sensors is usually available. However, the increasing deployment of autonomous and/or expendable instruments requires characterization of sensor response prior to use, as satellite transmission of the complete raw time-series is presently impractical. Moreover, $a$ priori determination of response characteristics is useful for fine- and microstructure studies as well as development of new sensors.

One body of work that systematically studied the response characteristics of conductivity cells was performed in a salt-stratified tank, in which a sharp interface was maintained between two mixed layers by the turbulence generated by oscillating grids (Gregg et al., 1981, 1982; Gregg and Hess, 1985). However, these tests failed to detect the substantial thermal mass problems of one conductivity cell (Lueck and Picklo, 1990; Lueck, 1990), since there was little or no temperature difference across the salt interface in most of the trials. Others have used quickly removed barriers between different water types to generate a step change in properties (Fozdar et al., 1985), but the set-up required limits the ease of repeat measurements. Inspired by the sharpness of oceanic salt-finger interfaces that so clearly revealed the thermal mass problem to Lueck (1990), we have developed a simple technique for maintaining a very sharp temperature and salinity step between two mixed layers in a large tank using the principles of double-diffusive convection (Schmitt, 1994). In conjunction with a system for transiting CTD sensors through the interface at various speeds, the tank has proven to be very useful for determining sensor dynamic response characteristics. Since double-diffusive interfaces occur widely in the ocean, and provide some of the most challenging situations for salinity spiking, a CTD tuned for lag correction in this tank should perform well at sea. The system described is easy to maintain with modest energy input, so that a sharp interface with a large step in temperature and salinity is available for testing on a nearly continuous basis with minimal operator attention.

In Section 2 the relevant principles of double diffusion are reviewed, followed by a description of the double-diffusive interface tank and its performance. Section 3 contains: a discussion of dynamic response tests with an example, the procedure for estimating the response time, its variation with fall-rate, the effects of finite interface thickness on the tests, the application of filters to correct the data, and the effects of the thermal mass of the conductivity cell. Most sensor-response results are presented for a CTD designed for a profiling float but the fall-rate response sensitivity is examined for standard CTD temperature sensors. An appendix provides a relationship for adapting a single pole filter sensor response to the coarse temporal sampling often used in autonomous vehicles. 


\section{The double-diffusive interface tank}

\section{a. Double-diffusive theory}

As Lueck and Picklo (1990) discovered, a thermohaline staircase is an ideal place to test the dynamic response of CTD systems. The characteristic mixed layers with near uniform properties separated by thin interfaces with strong gradients approximates ideal step changes in $T$ and $S$ with depth. Such staircases are maintained by double-diffusive convection (Schmitt, 1994). In the case studied by Lueck and Picklo, salt fingering was the active agent driving the convection. That is, both temperature and salinity decreased with depth, and the fact that the molecular diffusion of heat is 100 times faster than the diffusion of salt allows adjacent water parcels to come into thermal equilibrium while still having a substantial salinity difference. The resulting vertical convection releases energy in the unstable distribution of salt via centimeter-scale salt fingers in the high gradient interfaces (Stern, 1960). This unstable buoyancy flux in turn drives a large-scale overturning convection in the adjacent layers, keeping them well mixed and uniform in properties (Stern and Turner, 1969). If the appropriate fluxes are maintained at the boundaries, then the layers remain well mixed and the interface remains sharp (Schmitt, 1979). However, maintenance of a boundary salt flux in the laboratory is problematic. The fluxes due to salt fingers are fairly large, and achievement of a steady state heat-salt finger experiment even in small laboratory tanks has not yet been accomplished. Also, a salt fingering interface is generally thicker than a "diffusive-convection" interface, and thus will not provide the thinnest interface possible. Finally, the microstructure of the fingers themselves would add a variable element to the interface $T$ and $S$ profiles.

To avoid many of the foregoing problems, the other form of double diffusion, the so-called "diffusive-convection" system, was chosen for our laboratory tank. This instability arises when cold, fresh water lies above warm, salty (and denser) water. The salt distribution maintains the overall static stability while the faster diffusion of heat across the thin interface drives convection in the adjacent mixed layers. The theoretical potential for this instability was noted in a footnote by Stern (1960) and demonstrated in the laboratory by Turner and Stommel (1964). Salt is transported across a diffusive interface at a slow rate, allowing long duration runs in reasonably sized tanks. Also, it is straightforward to set up the two-layer salinity stratification and provide the boundary fluxes of heat, which is the driving agent for the diffusive convection.

Diffusive convection initially arises as an oscillatory "over stability" in contrast to the direct convective mode of salt fingers (Shirtcliffe, 1967). However, it quickly reaches amplitudes where steady convection is maintained in mixed layers by thermal conduction across a thin interface. The weaker salt diffusion acts as a brake on the system, while the salinity contrast maintains the gravitational stability of the interface. When a stable salt gradient is heated from below (Turner, 1968), a series of mixed layers and interfaces forms staircase profiles in temperature and salinity. Heat supplied by intruded warm water at mid-depth is believed to cause the thermohaline steps observed in Arctic (Neal et al., 1969) and Antarctic (Muench et al., 1990) regions. The diffusive-convection system can be 
analyzed in terms of classic Rayleigh-Bernard convection, with the presence of salt delaying the onset of convection. The ratio of salt flux to heat flux is low (compared to salt fingers), since the transport across the interface is governed by molecular diffusion, so long as the density contrast is large. Large density contrast double-diffusive stratifications are also used in solar pond energy collectors (Tabor, 1981).

The overall stability of a diffusive-convective system is governed by the density ratio, $R_{\rho}=(\beta \Delta S / \alpha \Delta T)$ where $\alpha=-(1 / \rho)(\partial \rho / \partial T), \beta=(1 / \rho)(\partial \rho / \partial S)$ are the thermal expansion and haline contraction coefficients, and $\Delta T, \Delta S$ are the temperature and salinity differences across the interface. Fluxes are largest when $R_{\rho}$ is near one. Also, the ratio of salt buoyancy flux to thermal buoyancy flux approaches one in this limit (Turner, 1965), whereas at higher $R_{\rho}$ it tends toward the square root of the salt to heat diffusivity ratio $\left(\sqrt{\kappa_{S} / \kappa_{T}} \cong 0.1\right)$ (Veronis, 1968; Linden and Shirtcliffe, 1978). Thus, to preserve the temperature contrast in the tank as long as possible, it is most convenient to work at a high density ratio $\left(R_{\rho}>4\right)$; which is achieved with a large salinity change $(\Delta S)$. Such a system is also easy to set up and maintain because of the large gravitational stability, and provides for sharp step-profiles lasting several weeks of continuous running; longer if the thermal forcing is turned off during periods of non-use. The heating and cooling drives convection in the two layers, which keeps both well stirred and uniform in properties, without the need for oscillating grids. When fully developed, a sharp interface is maintained between the two layers, across which thermal conduction takes place, with little salt diffusion because of the low flux ratio. The diffusive interface will migrate upward slowly with time, an effect thought to be due to the nonlinearity of the equation of state (McDougall, 1981). By traversing CTD sensors through the tank at various speeds, one has an ideal test platform for investigating sensor dynamic response and tuning lag-correction algorithms.

\section{b. Tank construction}

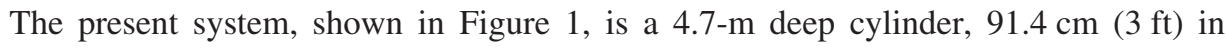
diameter, with a $2.54-\mathrm{cm}$ (1-in) wall thickness. This is a standard-size poly-vinyl-chloride (PVC) waste-water pipe. The lower end is sealed with an anodized aluminum plate, $2.54 \mathrm{~cm}(1 \mathrm{in})$ thick. The working platform at the top of the tank is a $2.5 \mathrm{~m} \times 2.5 \mathrm{~m}(8 \mathrm{ft} \times$ $8 \mathrm{ft})$ plywood deck constructed $3.6 \mathrm{~m}(12 \mathrm{ft})$ above ground level. A metal stairway and trapdoor provide access. The tank/platform assembly can be moved by heavy-duty forklift when the tank is empty.

The heating is supplied through a flexible mat resistive heating element (Electro-Flex Heat Inc., Bloomfield, CT) held against the underside of the aluminum plate by foam insulation. It is powered by AC line voltage reduced through a variable transformer and controlled by a thermostat sensor in the lower layer. Typically about $400 \mathrm{~W}$ is dissipated in the mat under the tank; it is rated to $2200 \mathrm{~W}$. Initial runs achieved temperature differences of $3-4^{\circ} \mathrm{C}$ when only actively heating the lower layer. In such runs the upper layer would slowly warm and lose heat to the atmosphere causing the interface to weaken over time. Later, a cooling system was devised for the upper layer that allowed steady state 


\section{Double-diffusive Interface Tank}

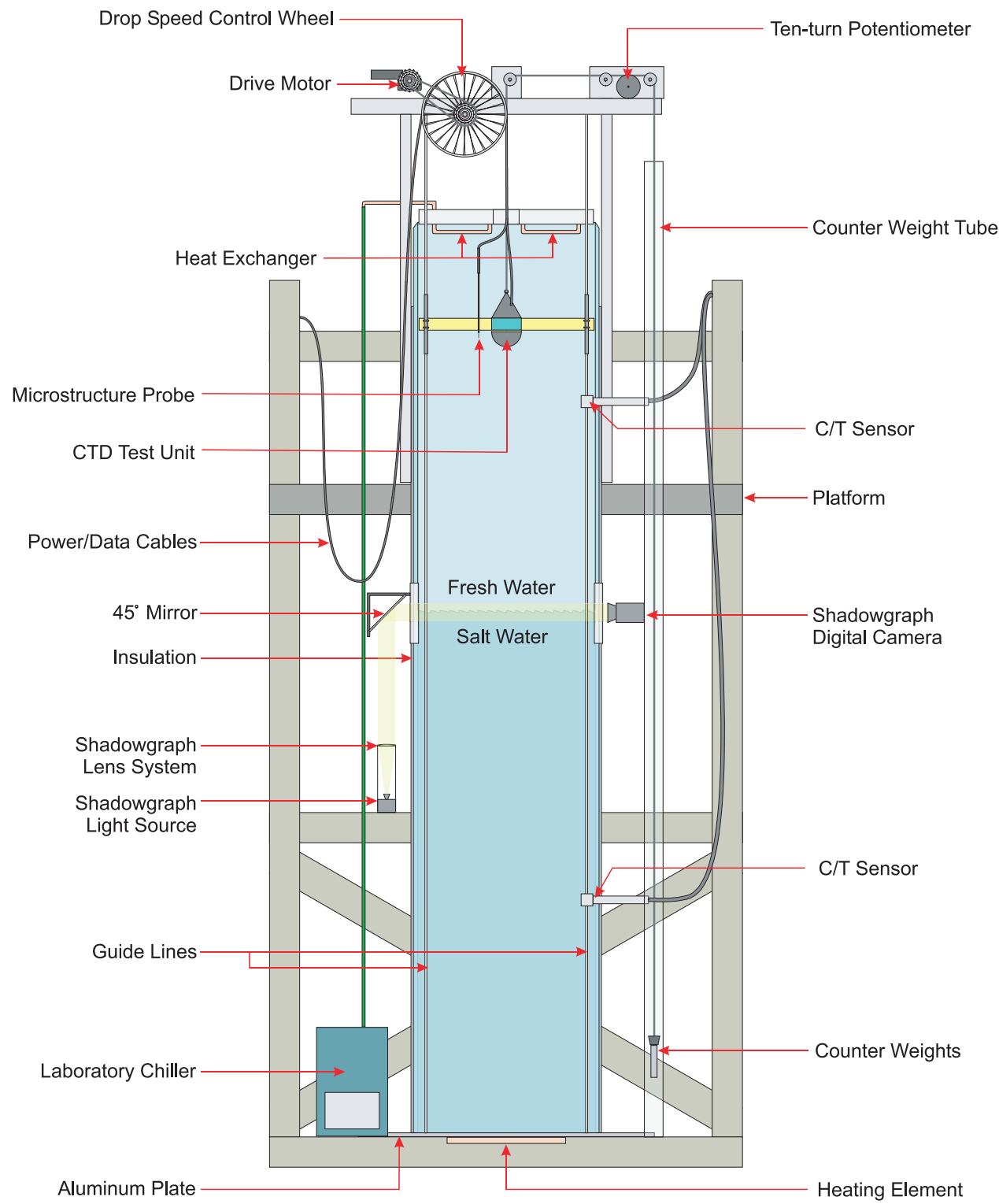

Figure 1. Schematic of the double-diffusive interface tank. The PVC tank stands 4.7-m high and has an internal diameter of $91 \mathrm{~cm}$. Aluminized bubble wrap provides insulation. A stairway at the rear provides access to the working platform. The speed of the bicycle wheel controls the fall rate of sensors through the sharp interface. The counter weights travel within the clear tubing to the right. 
temperature contrasts of $10-15^{\circ} \mathrm{C}$ to be maintained for several weeks at a time. The upper layer is cooled by a heat exchanger comprised of 2 lengths of coiled copper tubing mounted beneath closed cell foam, which acts both as floatation and insulation at the water surface. Cold water is circulated through the heat exchanger by a laboratory chiller ("Coolflow 75," Neslab, Inc., Newington, NH), which has a rated capacity of $700 \mathrm{~W}$. Heat losses out the sides and top of the tank are decreased by aluminized bubble wrap sheet insulation wrapped around the PVC pipe and the foam floatation at the surface. Application of $\sim 400 \mathrm{~W}$ of heating and cooling brings the lower layer to about $5^{\circ} \mathrm{C}$ above room temperature and the upper layer to $5^{\circ} \mathrm{C}$ below room temperature. Alternatively, the substitution of a higher capacity chiller (Neslab "Coolflow HX-300") allows the achievement of $15-20^{\circ} \mathrm{C}$ temperature differences. If the tank is continuously heated/cooled at this rate with an initial salinity difference of order $10 \mathrm{psu}$, then the temperature and salinity contrasts slowly decay and the stratification disappears in about two weeks. Use of a thermostat in the lower warm layer to control the heating, and fixed temperature water in the upper coils, allows maintenance of a nearly constant temperature difference across the interface. If the density ratio is kept above 4 , then the transfer of salt is sufficiently slow that a substantial $T$ and $S$ step be preserved for several weeks. $R_{\rho}>4$ can be maintained by modest decreases in the differences of the two temperature controls. Alternatively, a complete shutdown of tank heating and cooling preserves the salt difference even longer. A sharp interface can then be obtained approximately 12 hours after restarting heating/ cooling. The tank is located in a large "high bay" (for overhead clearance) that provides only crude regulation of the room temperature as the large garage doors are frequently open, but we have not found this to significantly affect tank performance.

Fixed temperature and conductivity sensors (FSI digital OEM C-T sensors) are mounted through the tank sidewalls in removable fixtures to monitor temperature and salinity in the two layers. Their data are accessed via RS-232 interfaces connected to a laptop computer. Taps adjacent to the C-T sensors allow water samples to be drawn for salinity determination. The lower layer salinity is typically set to be $10-15$ using commercially available "Sea Salt" manufactured by Lake Products Co. (Maryland Heights, MO), the upper layer is fresh water slowly introduced by trickling over a removable disc of foam floatation. The upper layer salinity often starts out below the limit ( 2.0) of the Practical Salinity Scale of 1978 (PSS78) but this does not affect the determination of thermometer time constants. Similarly, conductivity cells are inherently linear and are designed to handle low salinities, so we do not believe that the low average salinity influences the results. In the future we plan to relocate the tank near a filtered seawater source, which would allow use of oceanic range salinities. Several taps in the side of the tank allow for selective withdrawal of fluid at mid depth, which can be used to remove a thick interface if necessary. Also, when set-up with a simple siphon/overflow system, fresh water can be introduced to the upper layer so as to displace mixed water at the depth of the tap in order to decrease upper layer salinity, or thin or deepen the interface as needed. (Diffusive interfaces migrate upward over time.) The mechanism for dropping sensors through the interface uses an aluminum frame 
traversing the center of the tank as the holder for test CTDs. It is attached at each end to short sections of plastic piping (.635 cm i.d. PVC) gliding along taut nylon lines extending from an overhead frame to the bottom of the tank. Stainless steel springs $(30.5-\mathrm{cm}$ long) mounted around each line at the bottom serve to stop the framework before sensors can impact the bottom plate. Instruments are mounted to the frame and counterweighted by a variable number of oceanographic cable "messengers" attached to the other end of a thin steel cable (fishing line leader). This cable passes around a 0.5-m circumference pulley attached to a ten-turn potentiometer. A voltage divider circuit allows the potentiometer to be used as a depth scale. A metric tape measure extending the length of the counterweight travel tube (12.7-cm diameter clear plastic pipe (sediment core liner)) allows calibration of the depth scale. The fall-speed of the sensor frame is controlled by the payout of the data cable servicing the instruments on the frame. This is done using a $66-\mathrm{cm}$-diameter bicycle wheel lined with double-sided tape. Its rotation rate is controlled by a variable speed $90 \mathrm{~V}$ DC geared motor connected to the wheel by two seven-position bicycle sprockets and a drive chain. Available gearing allows the wheel to turn over nearly a tenfold range of ratios ( 0.3235 to 3.091 ) relative to the motor. Controlled speeds of $1 \mathrm{~cm} / \mathrm{s}$ to $270 \mathrm{~cm} / \mathrm{s}$ are possible with small, lightweight sensors; the inertia and drag of larger instruments limits the speed attained. Most usage to date has been in the $10-100 \mathrm{~cm} / \mathrm{s}$ range. The sensor and frame are counter-weighted to have a free-fall terminal velocity that is moderately greater than the desired test speed, so that the friction of the bicycle wheel on the data cable is sufficient to control the drop of the instrument. The other side of the data cable simply drapes down outside the tank. For tests of float CTD heads, a conical plastic fairing was used to diminish the trailing wake of the flat end plate of the pressure housing. This served to minimize the volume of fluid carried across the interface during runs, thus helping to preserve the salinity contrast and keep the interface thin.

In order to assess the detailed structure of temperature and salinity profiles in the tank, a high-resolution microstructure probe is used. The probe ("Model 125 MicroScale Conductivity and Temperature Instrument" manufactured by Precision Measurement Engineering, Encinitas, CA) consists of a miniature 4-electrode conductivity cell in close proximity to a fast responding thermistor (FP-07). The cabling for the microstructure probes is bundled with the power and communications cable for the test CTD (as needed; internally recording CTDs requires no cable) and passed over the bicycle wheel. The microstructure and position data are digitized and logged at $200 \mathrm{~Hz}$ using a 16-bit A/D converter on a PCMCIA card in a laptop computer. A Butterworth filter with cutoff at $100 \mathrm{~Hz}$ prevents aliasing of the digitized microstructure data. The CTD data are monitored using a digital RS 232 communications line to the laptop; a number of different sampling rates have characterized the CTD units tested to date, and they are sometimes run in an internally recording mode, with data offloaded after each run, in order to achieve the fastest sampling rate.

Because the passage of a test CTD causes some disruption of the interface and produces microstructure in the mixed layers, successive runs must be spaced in time. To establish 


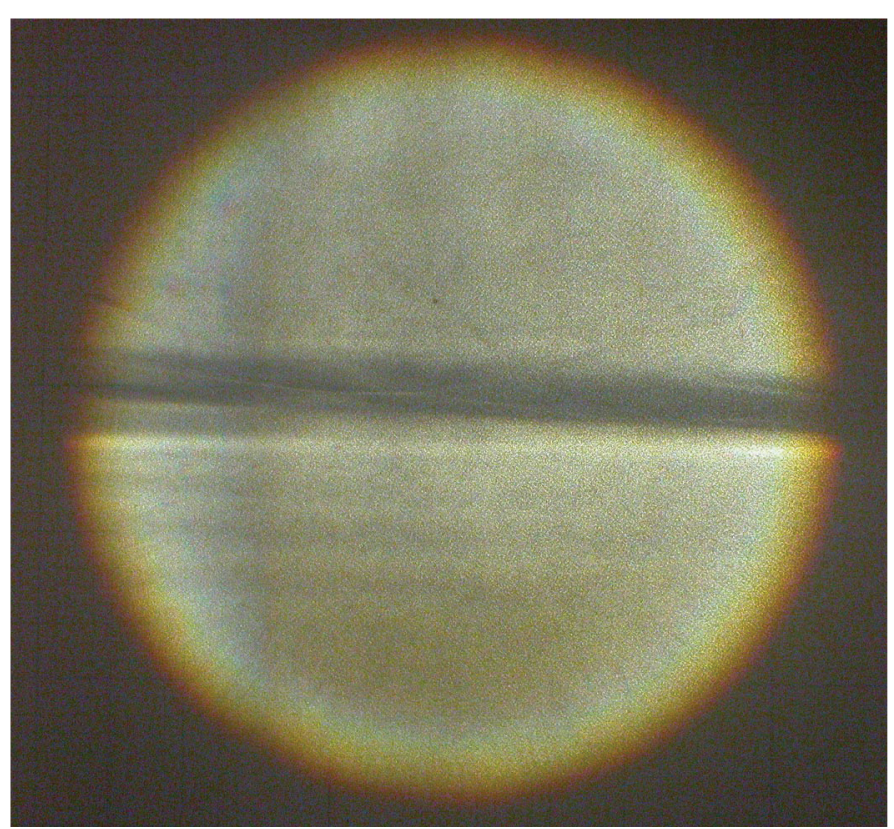

Figure 2. Shadowgraph image of the diffusive interface. The illuminated area is $15 \mathrm{~cm}$ in diameter. The dark-light transition line represents the position of the maximum vertical gradients in index of refraction and density. The beam can be moved vertically through a range of $43 \mathrm{~cm}$ in order to follow the upward migration of an interface with time, or scan for multiple interfaces.

when it is appropriate to make the next run, it is desirable to monitor the state of the interface noninvasively. We found that an inexpensive commercial echo sounder was helpful in this regard. The unit used is a "Fishfinder 240" (Garmin, Inc. Olathe, KS); it has a $200-\mathrm{kHz}$ frequency and a narrow beam transducer $\left(12^{\circ}\right)$, to minimize echoes from the sides of the tank. The backscattered acoustic returns are caused by the sound-speed and density variations produced by temperature and salinity gradients in the tank. Since positive anomalies of both temperature and salinity lead to positive sound speed anomalies, there is a strong step in sound speed across the interface. The position and intensity of the interface, convective plumes moving in the layers due to heating and cooling, and the microstructure generated by passage of the test sensors are all easily discernable. This allows one to gauge the readiness of the tank for additional tests without disturbing the interface with a probe. We have also installed a shadowgraph system for the same purposes. Two parallel 1.27-cm-thick glass windows situated on opposite tank walls allow the projection of a 15-cm-diameter beam of collimated light horizontally across the middle of the tank. When projected onto tracing paper the resulting image provides a direct view of the interface sharpness and readiness for test drops (Fig. 2). The window height of $40 \mathrm{~cm}$ and a traversing mechanism for a front surface mirror allow limited vertical travel in the 
position of the shadowgraph beam. This permits limited tracking of the upward migration of the interface.

\section{c. Tank performance}

Sample temperature and conductivity profiles from the microstructure probes are shown in Figure 3 for a setup with heating below and cooling above. CTD sensors were profiled through the interface at an average speed of $7.5 \mathrm{~cm} / \mathrm{s}$; Figures $3 \mathrm{c}$ and $\mathrm{d}$ illustrate the fall-rate and depth variations for this drop. The overall layer homogeneity and the sharpness of the interface is revealed by the microstructure probes (Fig. 3a, b), which are calibrated for each run against the fixed $\mathrm{C}$ - T sensors in each layer. The temperature change of nearly $10^{\circ} \mathrm{C}$ was achieved over $\sim 1.5 \mathrm{~cm}$ : a vertical temperature gradient of $700^{\circ} \mathrm{C} / \mathrm{m}$ (Fig. 3b). The change in conductivity was nearly $20 \mathrm{mS} / \mathrm{cm}$, and the slightly more rapid response of the microstructure conductivity probe relative to the temperature sensor can be seen, though it may have a small thermal mass effect, as indicated by the slow final approach to the lower layer values.

The large temperature gradient obtained across the double-diffusive interface is consistent with molecular conduction being the primary means of heat transport from the lower to the upper layer.

That is, we can estimate the conductive heat flux from the observed gradient, the thermal conductivity of sea water $\left(\kappa_{T}=1.424 \times 10^{-7} \mathrm{~m}^{2} / \mathrm{s}\right)$ and the tank area $\left(A=0.66 \mathrm{~m}^{2}\right)$ :

$$
Q=A \rho C_{p} \kappa_{T} \frac{d T}{d z} .
$$

For the estimated interfacial temperature gradient of $700^{\circ} \mathrm{C} / \mathrm{m}$, the calculated heat flux is 272 Watts. This indicates that nearly $70 \%$ of the 400 Watts of heat supplied to the lower layer was transmitted through the interface in this run, with the remainder lost through the tank sidewalls and the external area of the aluminum bottom plate, since the layer temperatures were approximately constant. The sharpness of the interface, and the homogeneity of the mixed layers, means that probes dropped through the tank will experience a step change in temperature (and salinity), particularly since the sampling volume of most sensing systems is larger than one centimeter. Though some microstructure is apparent in the mixed layers, presumably due to the convective movement of heat-transporting water parcels, it is small relative to the large temperature jump across the interface. In some of the following analysis we utilize the observed sharpness of the temperature interface to assume a step temperature response solution. The effect of a finite width step is examined later.

\section{Dynamic response tests}

\section{a. General considerations}

The task of computing salinity from measurements of temperature and conductivity is complicated by their differing responses due to: (1) simple time delays or lags due to physical 
April 3,2000 , Conductivity and Temperature
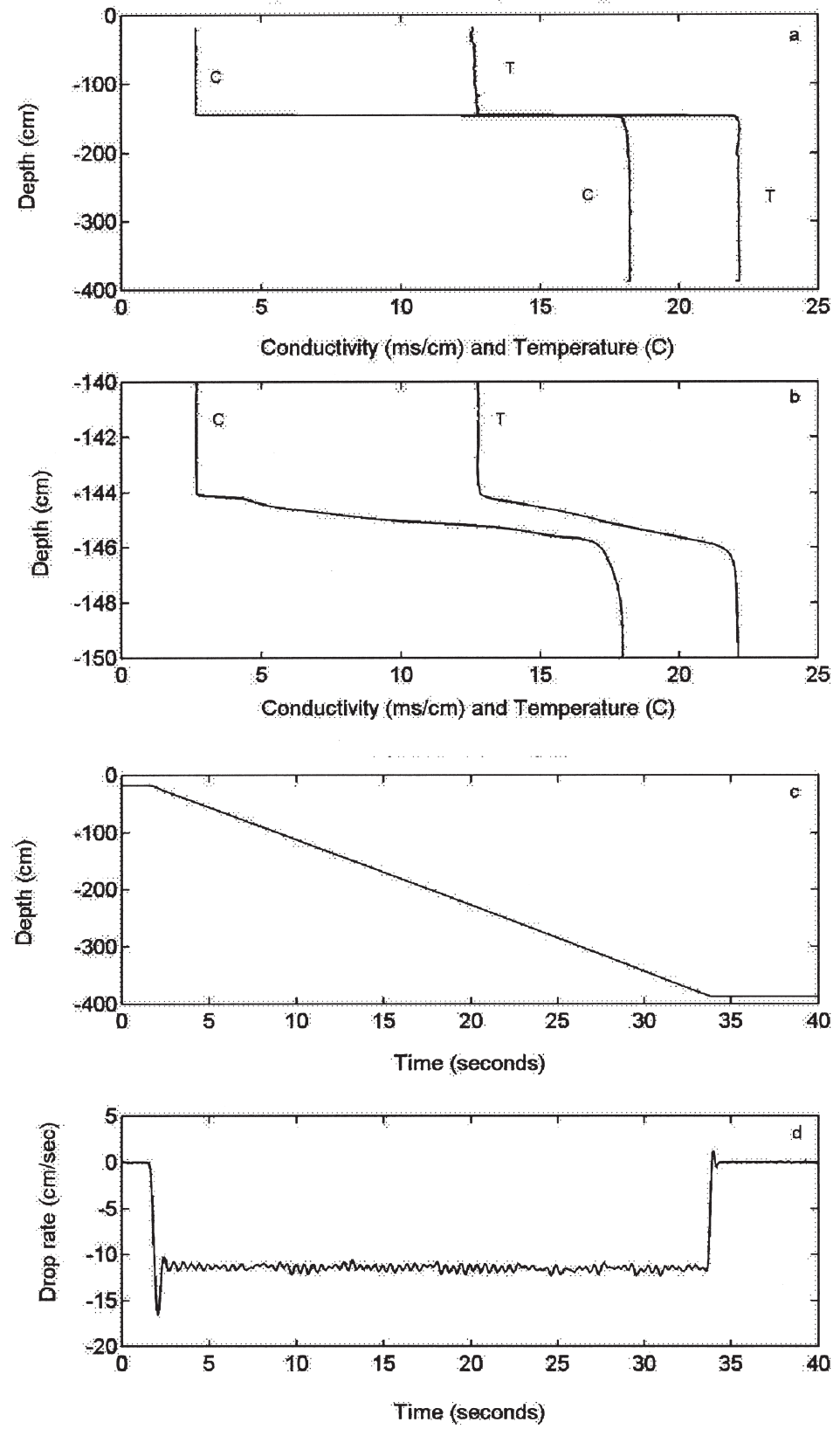

Figure 3. (a) Profiles obtained with the microstructure sensors of conductivity and temperature through the double-diffusive plunge tank from April 3, 2000. (b) Expanded view of the interface between the two layers for the April 3 run. The interface is little more than 1-cm thick; the temperature gradient is approximately $700^{\circ} \mathrm{C} / \mathrm{m}$. (c) Displacement and (d) drop rate versus time for a run on April 3, 2000. Fall rate oscillations are due to the impulsive start of the bicycle drive wheel and irregularities in payout of the data cable. 
positioning of the probes or electronic digitization sequence, (2) the time it takes the sensors to respond to changes in the environment, and (3) impacts the probes themselves have on the measurement (such as effects due to the thermal mass of conductivity cells). Also, we must expect that all of these issues will be speed dependent. Both conductivity cells and temperature sensors introduce filtering but there is an intrinsic difference in the nature of their responses; the temperature sensor introduces a phase shift while the conductivity sensor does not. The primary conductivity response is simply due to the flushing of the sample volume by movement of the cell through the water. This produces a sensor response that is, to first-order, a boxcar filter having a filter length in time $(\lambda)$ equal to the effective flushing length of the cell $(L)$ divided by the instruments fall rate $(w) ; \lambda=L / w$. The boxcar filter introduces no phase shift as a function of frequency $(\omega)$ to the conductivity data but does reduce the amplitude of the conductivity variations as $|\sin (\omega \lambda) / \omega \lambda|$. The effective flushing length is approximately the cell length, although Topham and Perkins (1988) discuss conditions under which the flushing length can be greater, such as when the field of a cell extends beyond the cell itself, as is the case with the inductive cell examined here. By contrast, the temperature sensor involves the diffusion of heat through a fluid boundary layer and the physical structure of the probe. This introduces a delayed response in the measured temperature signal. One scheme for matching the response characteristics of the two probes is to apply a recursive filter to the conductivity data to impose a phase shift similar to that of the temperature probe. On the other hand, when filtering temperature to match the flushing time of conductivity, we recommend filtering the temperature channel with a boxcar filter having no phase shift, rather than a recursive filter as suggested by Giles and McDougall (1986), since the conductivity sampling volume is essentially a boxcar, and a phase shift should not be necessary.

\section{b. An example}

Profiles of temperature and conductivity were obtained from CTDs designed for autonomous floats; these instruments must execute lag correction and pressure averaging in-situ, so require prior determination of sensor time constants. In general these instruments have rather slow sample rates, so we focus on estimation of time constants and matching of the temperature and conductivity responses, rather than the frequency response that could be determined for more rapidly sampled microstructure sensors (Lueck et al., 1977; Gregg and Meagher, 1980). Here we discuss results of tests on the Excell CTD developed by FSI for use on profiling floats and include examples with and without the additional thermal contrast provided by the chiller. The Excell temperature probe consists of a 100-ohm platinum wire element, pressure protected by a thin-walled cylindrical titanium housing mounted adjacent to the conductivity cell at its centerline and separated horizontally by approximately $3.0 \mathrm{~cm}$ from the conductivity cell axis. The temperature probe thus does not sense the temperature of the volume of seawater inside the cell; in our analysis we neglect any real differences in the water temperatures inside and immediately adjacent to the cell due to microstructure.

The Excell CTD has a sampling interval of $\Delta=0.357 \mathrm{~s}$. This compares with a typical ship-lowered CTD system such as the Mark IIIC CTD with $\Delta=0.03$ s or the SBE 911 plus 

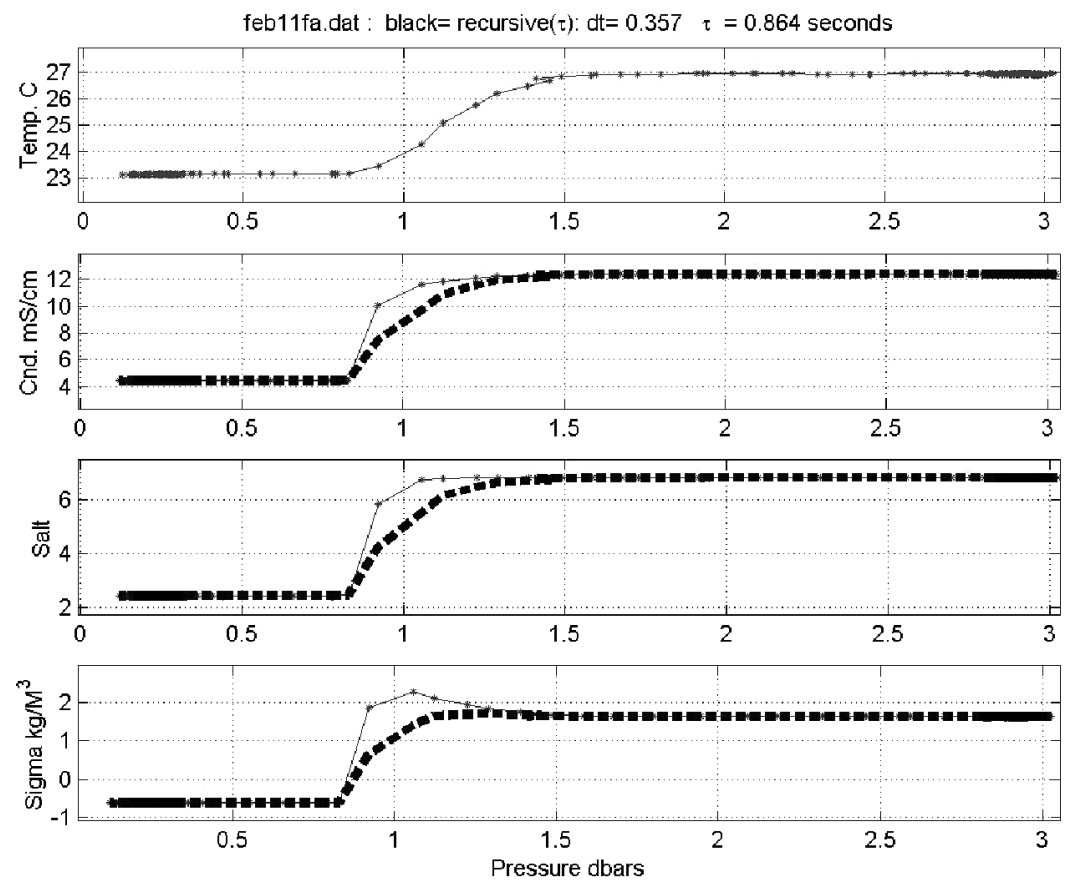

Figure 4. (a-d, top to bottom) Four panel plot of temperature, conductivity, salinity, and density versus pressure from the first 11 Feb. plunge Excell \#1318. Panels b, c, and d have over plots of no lag (= light solid line); recursive filtered (= thick dashed line). Note the density overshoot for solid (no lag) curve around 1 decibar associated with the step in temperature and salinity corrected by the filter. The Excell's raw pressure is used as the horizontal axis which accounts for the irregular spacing of the points.

with $\Delta=0.04 \mathrm{~s}$. The Excell employs an inductive conductivity cell made of alumina with a length and external diameter of $4.5 \mathrm{~cm}$ and internal diameter of $2.4 \mathrm{~cm}$. The conductivity sensor measures the seawater conductance in the cell interior with a smaller contribution from the surrounding seawater. Ship-lowered CTD systems have a typical lowering rate of $100 \mathrm{~cm} / \mathrm{sec}$, which would give a minimum flushing time of 0.045 seconds for the FSI conductivity cell. On the PALACE float vehicle a typical ascent speed of $\sim 10-15 \mathrm{~cm} / \mathrm{s}$ (Davis et al., 1992) is expected, which translates into a flushing time of $\sim 0.45$ seconds; thus, each conductivity sample from a float is roughly independent.

An example from Excell \#1318 traversing through the tank interface at a speed of $16.5 \mathrm{~cm} / \mathrm{s}$ is shown in Figure $4 \mathrm{a}-\mathrm{d}$. No chiller was used in the upper layer and therefore only a modest temperature change of about $4^{\circ} \mathrm{C}$ was achieved. For this run, the normal lag-correction filtering within the Excell has been disabled to illustrate the raw sensor response. The temperature (upper panel) probe clearly has a slower response than the unfiltered conductivity (solid curve in second panel). Temperature exponentially approaching the lower layer temperature value over $\sim 1.0 \mathrm{~m}$ causes incorrect salinities and densities to be calculated in the transition region. The density profile (bottom panel) overshoots in 
the transition to produce an apparent density inversion at the interface. While we expect no density gradients within the convecting layers, a density inversion of this magnitude within the interface is clearly an instrumental artifact.

The 1978 Practical Salinity Scale (PSS78) (UNESCO, 1981) is used to calculate salinity from measurements of conductivity, temperature, and pressure. Accurate salinity calculation requires conductivity, temperature and pressure data with matched response characteristics. The temperature response is controlled by the ability of the temperature probe's housing and surrounding boundary layer to lose or gain heat. One of the simplest models for describing the response of a temperature probe is the single pole filter equation (Fofonoff et al., 1974):

$$
\frac{d T(t)}{d t}=\frac{1}{\tau}\left(T_{0}(t)-T(t)\right)
$$

where $T(t)$ is the time series of measured temperature, $T_{0}(t)$ is the time series of ocean temperature, and $\tau$ equals the temperature probe response time.

Fofonoff et al. (1974) described a technique for speeding up the temperature measurement by rearranging Eq. (2) to solve for the ocean (true) temperature. They recommended estimating the temperature gradient $d T(t) / d t$ by linear least squares. Fofonoff et al. (1974) found that three observations in time were the optimum number of temperature values for estimating the gradient, but that further smoothing was usually required. A drawback to speeding up temperature is an increased temperature sensor noise level proportional to the magnitude of the response time $(\tau)$. In the formulations below, we solve Eq. (2) for the temporal response of the temperature probe in order to design recursive filters to delay the conductivity sensor data to match the temperature sensor. Middleton and Foster (1980) first suggested this approach, which is generally preferred over speeding up the temperature for most applications where resolution of finestructure is not required, since it also serves to reduce noise.

\section{c. Estimation of sensor response time}

i. Exponential response. The simplest model for the temporal response of a temperature sensor is a low-pass filter described by the solution to Eq. (2). The step response for a temperature change from $T_{0}$, the initial temperature, and the final temperature $\left(T_{f}\right)$ is given by:

$$
T(t)=T_{0}+\left(T_{f}-T_{0}\right) \cdot\left(1-e^{-(t / \tau)}\right) .
$$

We define the time origin $(t=0)$ to be at the top of the interface. Two approaches have been taken to fitting temperature response data to this exponential decay. The first relies on a simple logarithmic transformation to yield a linear fitting problem, the other employs a nonlinear fitting procedure. Both are sensitive to the range of data employed in the fit.

By rearranging and taking the natural logarithm of Eq. 3, we get: 


$$
\log \left[\frac{\left(T_{f}-T(t)\right)}{\left(T_{f}-T_{0}\right)}\right]=-\frac{t}{\tau} .
$$

The temperature time series $T(t)$ from a plunge test can be fit to Eq. 4 using a linear Least Squares Regression (LSR) procedure. The slope of the least squares fit of $\log \left[\left(T_{f}-\right.\right.$ $\left.T(t)) /\left(T_{f}-T_{0}\right)\right]$ against time yields the temperature sensor time constant $(1 / \tau)$ while the intercept or bias is interpretable as the time the sensor first encounters the step change in temperature. Note that the data being fit involves $\log \left(T_{f}-T(t)\right)$ which becomes indeterminate when the temperature $T(t)$ reaches $T_{f}$, so care must be exercised to exclude these data from the LSR. In practice this is easily accomplished by limiting the data to be fit to the transient portion of the record; we have used a criteria of using only data points removed by at least $5 \%$ of $\left(T_{f}-T_{0}\right)$ from the layer values, i.e.

$$
0.05<\frac{\left(T_{f}-T(t)\right)}{\left(T_{f}-T_{0}\right)}<0.95
$$

An alternative to the log-linear fit is to employ a nonlinear fitting procedure such as the Levenberg-Marquardt method (Press et al., 1986). This minimizes the variance of the fitted function by iteration; using the method of steepest descent far from the minimum and the curvature (Hessian) matrix near the minimum. Derivatives of the fitted function with respect to the bias and response time must be supplied, as well as initial guesses of these parameters. The method also requires an estimate of the standard deviation of the data points; by choosing to give most weight (smallest estimated error) to the gradient portion of the record a fitting procedure was developed to estimate the time constants using Eq. (3) rather than Eq. (4). Though this technique may occasionally settle on a local rather than global minimum of fit variance, visual inspection of the solutions assures the accuracy of the fit. Figure 5 illustrates one such fit.

ii. Finite step thickness effects. We also consider the effect of a nonideal step on the sensor response. Repeated runs in the tank can thicken the interface to 5-10 cm (Table 1) if there is insufficient time between runs to allow the convection to redevelop a sharp interface. The ideal time record of a temperature transition through a thick interface (of thickness $H$ and drop rate $w$ ) can be represented by a

$$
\begin{aligned}
T & =T_{0}, \text { for } t<0 \\
T & =\left[\frac{T_{f}-T_{0}}{\frac{H}{w}}\right] \cdot t, \text { for } 0<t<H / w \\
T & =T_{f}, \text { for } t>H / w .
\end{aligned}
$$

The single-pole temperature sensor response $\left(T_{r}\right)$ with time constant $(\tau)$ to the above temperature transient is: 


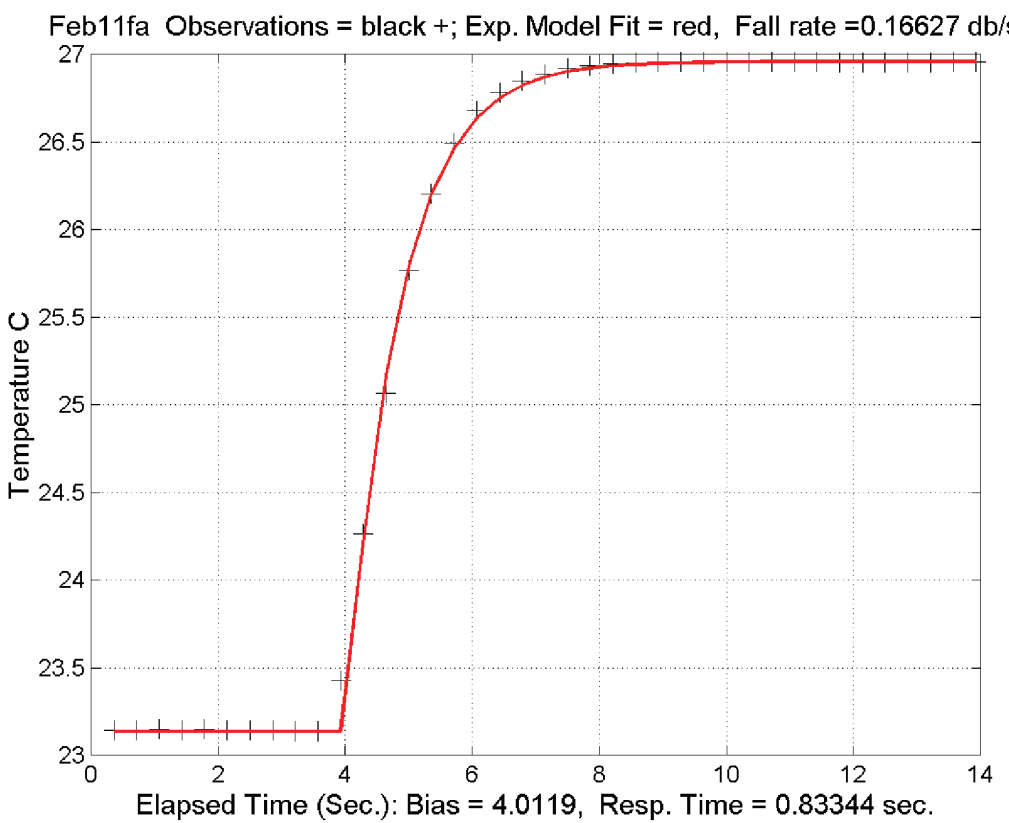

Figure 5. Temperature data (+) from an FSI Excell CTD (SN 1318) as it transits a temperature step on Feb. 11, 2000. The red curve is a nonlinear fit of the response time and bias to the exponential temperature ramp of Eq. 3.3, with the layer properties set by the layer extrema, and most weight given to the data points from the transient portion of the record. The best fit response time is $\tau=$ 0.857 seconds.

Table 1. Four successive lowering of Excell s/n 1318 on February 11, 2000. Response times $(\tau)$ for the log-linear fit use Eq. (4) over those data more than 5\% removed from the layer values. Those for the nonlinear fitting procedures use Eq. (3) or Eq. (6) with the most weight given to the gradient portion of the transient. The last 3 columns are data from the microstructure $\mathrm{C} / \mathrm{T}$ sensors that demonstrate the sharpness of the interface. Passage of the CTD increases the interface thickness from $\sim 2 \mathrm{~cm}$ to $\sim 8 \mathrm{~cm}$ in later runs but these still provide useful estimates of the thermometer response time, with only a modest increase in the estimated time constants.

Estimated response time $(\tau)$

\begin{tabular}{|c|c|c|c|c|c|c|}
\hline Run & $\begin{array}{c}\text { Log-linear } \\
\text { fit }\end{array}$ & $\begin{array}{l}\text { Nonlinear fit } \\
\text { to step/exp. }\end{array}$ & $\begin{array}{l}\text { Nonlinear fit } \\
\text { to ramp/exp. }\end{array}$ & $H$ & $\Delta T$ & $\begin{array}{l}\text { Max. } \\
d T / d z\end{array}$ \\
\hline$\#$ & $\mathrm{~s}$ & $\mathrm{~s}$ & $\mathrm{~s}$ & (m) & ${ }^{\circ} \mathrm{C}$ & ${ }^{\circ} \mathrm{C} / \mathrm{m}$ \\
\hline A & 0.826 & 0.833 & 0.815 & 0.025 & 3.689 & 149.85 \\
\hline B & 0.822 & 0.845 & 0.816 & 0.060 & 3.194 & 70.33 \\
\hline $\mathrm{C}$ & 0.859 & 0.852 & 0.850 & 0.079 & 3.044 & 38.69 \\
\hline D & 0.875 & 0.893 & 0.874 & 0.074 & 2.811 & 38.03 \\
\hline
\end{tabular}



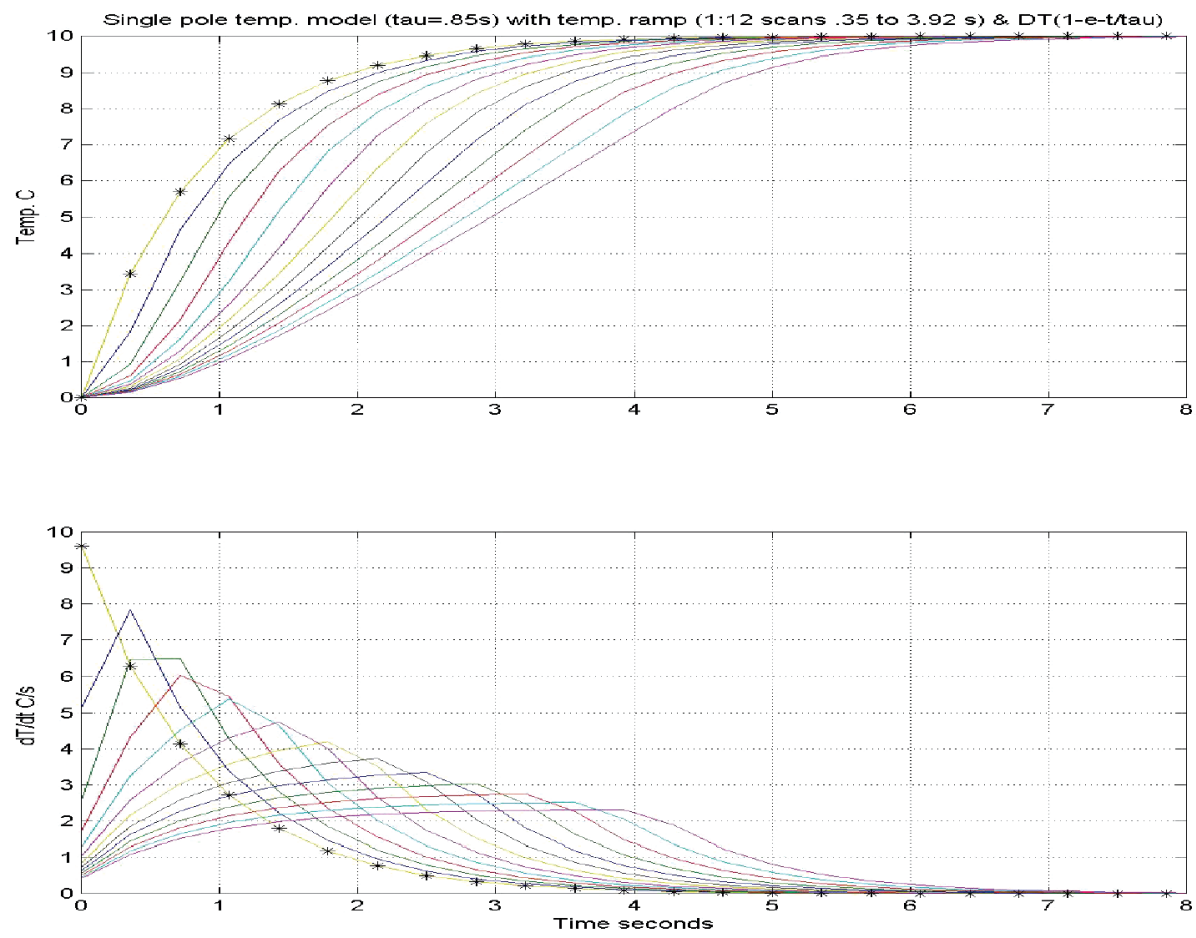

Figure 6. $(a-b)$ Upper panel is sensed temperature versus time for longer ramping intervals and lower panel shows maximum temperature gradient delayed increasing time intervals until temperature ramp end.

$$
\text { for } t<0: T_{r}=T_{0},
$$

$$
\text { for } 0<t<\frac{H}{w}: T_{r}=T_{0}+K \cdot\left[\tau \cdot e^{-(t / \tau)}+t-\tau\right] \text {, }
$$

$$
\text { for } t>\frac{H}{w}: T_{r}=T_{0}+K \cdot \frac{H}{w}+\left[T_{i}-K \cdot \frac{H}{w}\right] \cdot \exp \left[\frac{\frac{H}{w}-t}{\tau}\right] \text {, }
$$

where

$$
K=\left[\frac{\left(T_{f}-T_{0}\right) \cdot w}{H}\right], \text { and } T_{i}=K\left[\tau \cdot e^{-(H / \tau w)}+\left(\frac{H}{w}-\tau\right)\right]
$$

The temperature responses for discretely sampled analytic data series, traversing interfaces of increasing thickness $(H)$, are plotted in Figure 6a. Figure 6b displays the rate of change of sensed temperature; the maximum temperature gradient is increasingly displaced from the start of the interface as the interface thickens. The position of the 
maximum sensed gradient is close to $H / 2$. It was found that log-linear or nonlinear step/exponential fits to these analytic ramp temperature profiles yielded estimates of the time constant that were slightly larger than the prescribed time constant. However, the data can be fit to the analytic solutions in Eq. (6) using the Levenberg-Marquardt method. This requires an independent estimate of the interface thickness, $H$, which is available when microstructure data are separately recorded. Tests with analytic data showed that a nonlinear fit to the ramp solutions of Eq. (6) yields an accurate estimate of the response time, whereas fits to the simpler exponential form always overestimate the response time. Similar results are found with real data, as seen in Table 1 below. Thus, though best practice is to use runs where the interface is sharp, a thicker interface may be acceptable for high speed drops or slow responding sensors, and can be accommodated by nonlinear fitting to the ramp solutions of Eq. (6) when an independent estimate of interface thickness is available.

As an illustration of these points we further consider the FSI Excell, as designed for profiling floats. The results of four runs with Excell CTD s/n 1318 on February 11, 2000 are summarized in Table 1. The drop rate for the four runs was $16.5 \mathrm{~cm} / \mathrm{s}$ and varied by less than 5\%. The first run is plotted in Figure $3 a-d$. The dashed curves apply a response time ( $\tau=0.86 \mathrm{~s})$ to conductivity using the recursive filter given in formula (3.7). This eliminates the apparent instabilities of the density profile at the interface (dashed curve of Fig. 3d) noted earlier.

\section{d. Application of sensor response correction}

Having determined the response time of a temperature probe, one must devise a scheme to match the responses of the conductivity and pressure sensor data. A common approach is to digitally filter the conductivity and pressure data to yield a response comparable to that of the temperature channel (Ochoa, 1989). This is often done using a recursive filter to introduce the needed phase shift, such that:

$$
C(t)=a \cdot C(t-\Delta)+b \cdot C_{0}(t)
$$

where

$C(t)$ the output time series of filtered conductivity,

$C_{0}(t)$ the input time series of observed conductivity,

$\Delta$ is the sample interval,

$a$ is a weight related to the temperature sensor time constant, and

$b=(1-a)$.

The formula for $a$ suggested in Bendat and Piersol (1971) and also used in Millard (1982) is

$$
a=e^{-\Delta / \tau} \text {. }
$$

This formulation is valid when the sample interval is short compared with the sensor response time (i.e., $\tau \ll \Delta$ ). When $\tau \rightarrow \Delta$, Eq. (7) does not provide sufficient phase shift and 

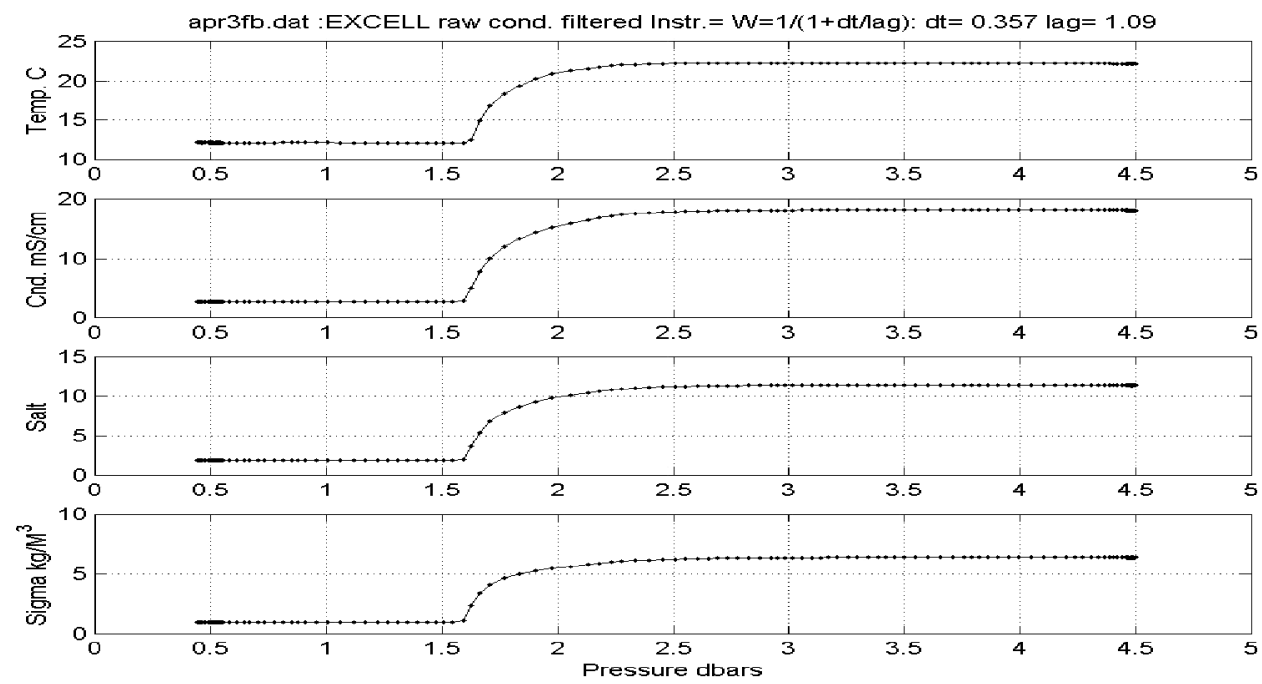

Figure 7. (a-d) Four panel plot of temperature, conductivity, salinity, and density versus pressure from the $2^{\text {nd }}$ April 3, 2000 plunge of Excell \#1321. The instrument default filtering with $\tau=0.93 \mathrm{~s}$ has been applied to conductivity and pressure.

the relation $a=[1 /(1+\Delta / \tau)]$ provides marginally better performance. Eq. (7) is the default lag correction scheme used in the FSI Excell.

An even better performing filter for slow sampling systems is the bilinear transform suggested by Mudge and Lueck (1994). This is applied as:

$$
C(t)=a \cdot C(t-\Delta)+b \cdot\left(C_{0}(t)+C_{0}(t-\Delta)\right)
$$

where:

$$
\begin{aligned}
& a=(1-2 b), \\
& b=\frac{1}{\left(1+2 \frac{\tau}{\Delta}\right)} .
\end{aligned}
$$

As seen in the Appendix (Figure A.1), the bilinear filter is better able to match the phase shift of the single pole response as the sampling interval approaches the response time of the sensor because of the use of both present and most recent values of the input signal.

Application of either of the above filters to the conductivity time series using the observed time constant of the thermometer may provide too much filtering in many cases. That is, the filtering applied based on the fitted thermometer time constant is sufficient to match a step function change in conductivity to the slower thermometer. However, 


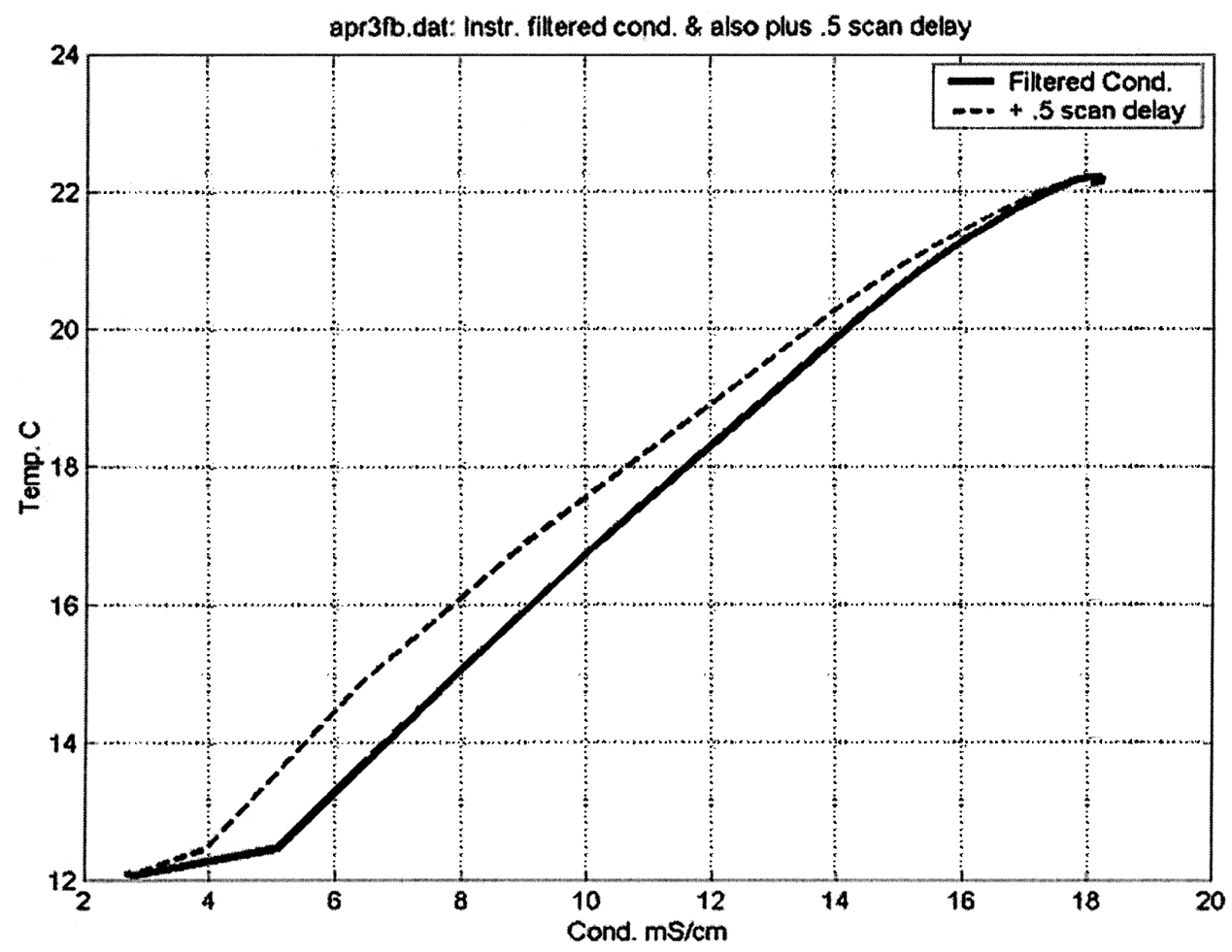

Figure 8. "Figure of merit" plot of $C$ versus $T$. (Solid) is observed instrument conductivity while (dashed) has a $0.5 \mathrm{scan}(0.179 \mathrm{~s})$ delay added to the conductivity, since its external field senses the interface prior to the thermometer.

conductivity sensors do not have such rapid response, but rather represent a finite-length boxcar filter as previously discussed. We have found the "conductivity-temperature" diagram a very useful diagnostic for optimizing the degree of lagging and filtering necessary to compute accurate salinities.

An example with Excell CTD data collected on April 3, 2000 having the conductivity data filtered with the instrument default lag value corresponding to $\tau=0.94$ seconds is shown in Figures $7 \mathrm{a}-\mathrm{d}$. The conductivity and derived salinity and density profiles shown in Figures $7 b-d$ look reasonable with no evidence of density inversions seen earlier in Figure 2 d, even though the default time constant value is slightly low, since this run was done at a slower speed (i.e., $\tau=0.94$ versus our estimate of 1.09 s). The April 3 data are associated with the microstructure probe example shown earlier in Figures $2 \mathrm{a}-\mathrm{d}$. The lagging procedure leaves the temperature unchanged and a least squares estimate of the temperature lag gives a slightly better response time of $\tau=1.09 \mathrm{~s}$ (model response is marked with square boxes while observations are marked as asterisks $(*))$. 


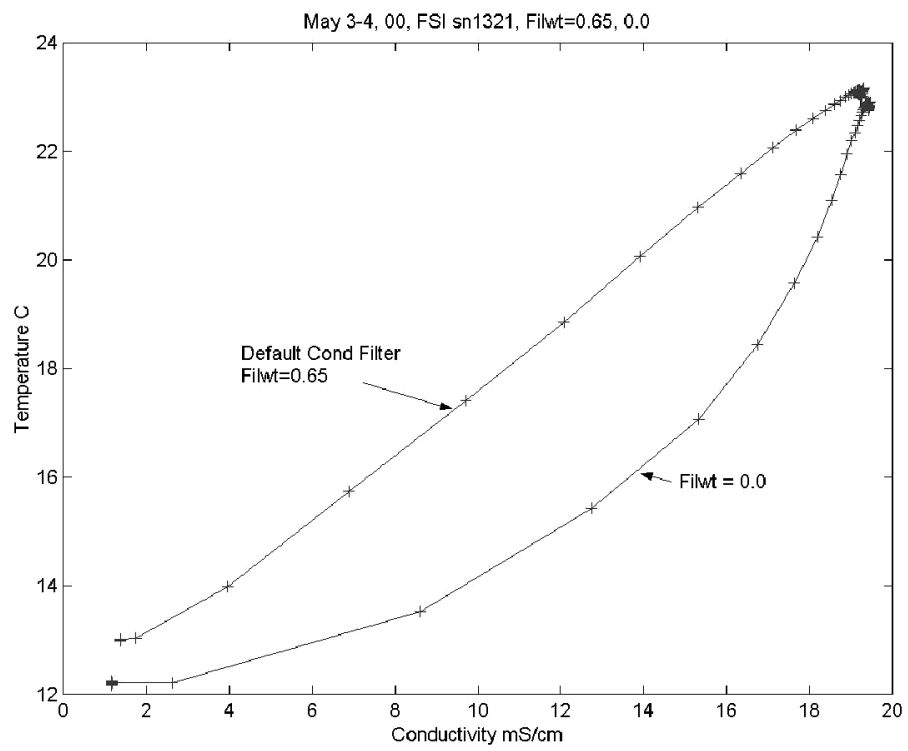

Figure 9. (a) The performance of FSI Excell \#1321 on two separate days, with and without the default conductivity filter applied. These were run at speeds of $\sim 12 \mathrm{~cm} / \mathrm{s}$, where the standard filter is seen to perform well, yielding a reasonably straight $C-T$ line between the values of the two mixed layers. Note the temperature contrast over $10^{\circ} \mathrm{C}$ with only slight changes in layer properties over one day.

A useful "figure of merit" for dynamic response studies involves plotting temperature versus conductivity for a given run. The form of the transition from one $\mathrm{T}, \mathrm{C}$ value representing the cold fresh, upper layer to that of the warm, salty, lower layer reveals much about the character of the $\mathrm{T}$ and $\mathrm{C}$ sensor dynamic response (Figs. 8, 9a,b). A slow thermometer is apparent as a concave curve, and various lags and filtering can be applied to achieve the ideal straight-line response of the system between the two layer properties. Note that at scales smaller than the interface we expect that a linear $\mathrm{C} / \mathrm{T}$ relation would not be expected due to the double diffusion within the interface. However, for all CTDs in general use, such scales (millimeters) are much smaller than the sampling volume of the sensors, so the linear relation represents optimal matching of $\mathrm{T}$ and $\mathrm{C}$ sensor responses. $\mathrm{A}$ nearly straight line, such as the dashed $\mathrm{C} / \mathrm{T}$ curve adjusted by a lag of 0.5 scans in Figure $8 \mathrm{~b}$, reveals well matched $\mathrm{T}$ and $\mathrm{C}$ sensors and assures that averaging to coarser resolution will yield an accurate estimate of the average properties. A simple time lag due to physical positioning or sampling sequence appears as a delayed temperature response (concave upward at the start of the run at low T, C). Effects due to the thermal mass of the conductivity cell appear as a delayed conductivity response as high T, C values in the lower layer are approached. 


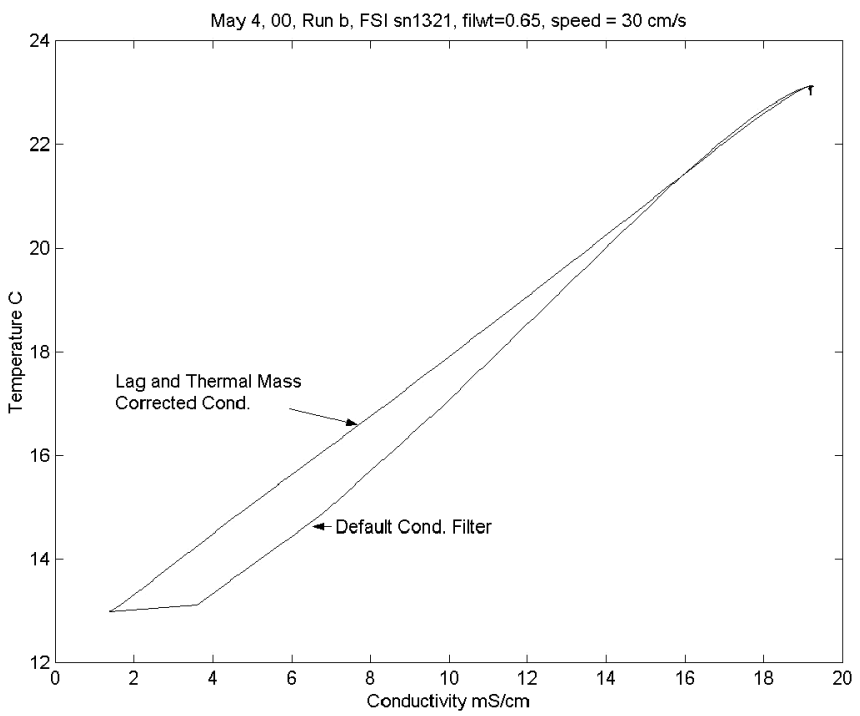

Figure 9. (b) A higher speed run $(\sim 30 \mathrm{~cm} / \mathrm{s})$ shows the need for lagging of the conductivity record relative to temperature, which corrects the $C-T$ curve at the beginning of the interface (low $C, T$ values). The thermal mass correction (with $a=0.4, b=0.6$ in Eq. 10) serves to straighten the $C-T$ curve at high $C, T$ values, where the sensor has entered the lower warm, salty layer, and the conductivity shows a perceptible lag relative to temperature.

\section{e. Thermal mass effect}

Lueck (1990) and Lueck and Picklo (1990) describe the thermal mass effect of conductivity cells. Because of the heat capacity of the cell, the temperature and thus the conductivity of the fluid in the measurement volume is altered by the presence of the cell. In our case the low temperature of the cell on passing through the interface causes a decrease in the measured conductivity, seen as a curvature in the $C-T$ plot near the high $C$, $\mathrm{T}$ values of the lower layer (Fig. 9b), as the measured conductivity more slowly approaches the layer value. Lueck (1990) finds that the thermal mass problem can be addressed by adding in a correction $\left(C_{T}\right)$ to the conductivity record that is proportional to the time rate of change of temperature. This can be applied as a discrete filter:

$$
\begin{aligned}
& C_{c}(i)=C_{f}(i)+C_{T}(i), \\
& C_{T}(i)=b C_{T}(i-1)+a\left(T_{l}(i)-T_{l}(i-1)\right) .
\end{aligned}
$$

Here the thermal mass correction is represented by $C_{T}$, the filtered conductivity by $C_{f}$, and the corrected conductivity by $C_{c}$. The magnitude of the correction $\left(C_{T}\right)$ depends on the rate of change of lagged temperature $\left(T_{l}\right)$ through a coefficient $(a)$ proportional to the temperature dependence of conductivity, the sampling rate, and the thermal anomaly 
generated by the cell, plus a memory term $(b)$ proportional to the thermal mass of the cell, that determines how long the thermal correction is applied.

For the FSI inductive head we find little need for a thermal mass correction at the $10-15 \mathrm{~cm} / \mathrm{s}$ speed of a float, but do find lagging and thermal mass corrections useful at higher translation speeds. Figure 9a shows diagnostic conductivity-temperature plots for slow speed $(\sim 12 \mathrm{~cm} / \mathrm{s})$ runs with and without the standard conductivity filter applied. Figure $9 \mathrm{~b}$ shows a higher speed run $(\sim 30 \mathrm{~cm} / \mathrm{s})$ with default conductivity filter (Eq. 7) only and with a fractional lag of the conductivity relative to temperature plus the thermal mass correction, with the weights $a$ and $b$ chosen by inspection. Morison et al. (1994) show that minimizing the salinity differences between rapid repeat up and down CTD casts is a practical way to optimize the selection of the weights when the appropriate field data are available. They also find that the form of the velocity dependence of the factors determining the weights is as expected, and suggest a more efficient implementation based on the estimated temperature of the water in the cell, rather than a corrected conductivity. Such issues could be readily evaluated in our tank.

\section{f. Response time variations with fall rate}

The different speed runs above with the Excell displayed markedly decreasing time constants as the velocity increased $(\tau=1.26 \mathrm{~s}$ at $w=0.11 \mathrm{~m} / \mathrm{s} ; \tau=0.83 \mathrm{~s}$ at $w=$ $0.29 \mathrm{~m} / \mathrm{s}$ ). This is to be expected from the thinning of the fluid boundary layer around the probe with higher velocity (Gregg and Meagher, 1980). We have further explored this dependence using paired temperature sensors on an Idronaut 'Ocean Seven' 319 CTD (Brugherio, Italy). The temperature sensors were successively lowered four times with drop rates ranging from $0.13 \mathrm{~m} / \mathrm{s}$ to $0.68 \mathrm{~m} / \mathrm{s}$. (These temperature probes are mounted with the long axis parallel to the flow, unlike the "perpendicular to flow" orientation of the FSI thermometer.) The sample rate for the Idronaut 319 is $12 \mathrm{~Hz}$, which provides roughly a factor of five faster time resolution than the Excell. Both temperature probes appear well described by the single pole model at a drop rate of $0.47 \mathrm{~m} / \mathrm{s}$ and the derived response time values of the probes are matched to within 0.01 seconds. The results of the four drop rates $(w)$ tested (Fig. 10) show a substantial and systematic change in estimated time constant as a function of drop rate $(w)$ for both temperature sensors. A fall rate scaling for the time constant close to $w^{-1 / 2}$ is observed and is expected from the behavior of high Reynolds number boundary layer thickness (Lueck et al., 1977). The Reynolds number for these probes was order $10^{3}$. There is evidence that at lower Reynolds numbers (i.e., slower speeds or smaller probes) the time response may vary as $w^{-1 / 3}$ (Gregg and Meagher, 1980) though this has not yet been investigated in this tank. The results suggest that a speed dependent filter could be designed for most CTDs that takes into account the faster response of the thermometer at higher fall rates. 


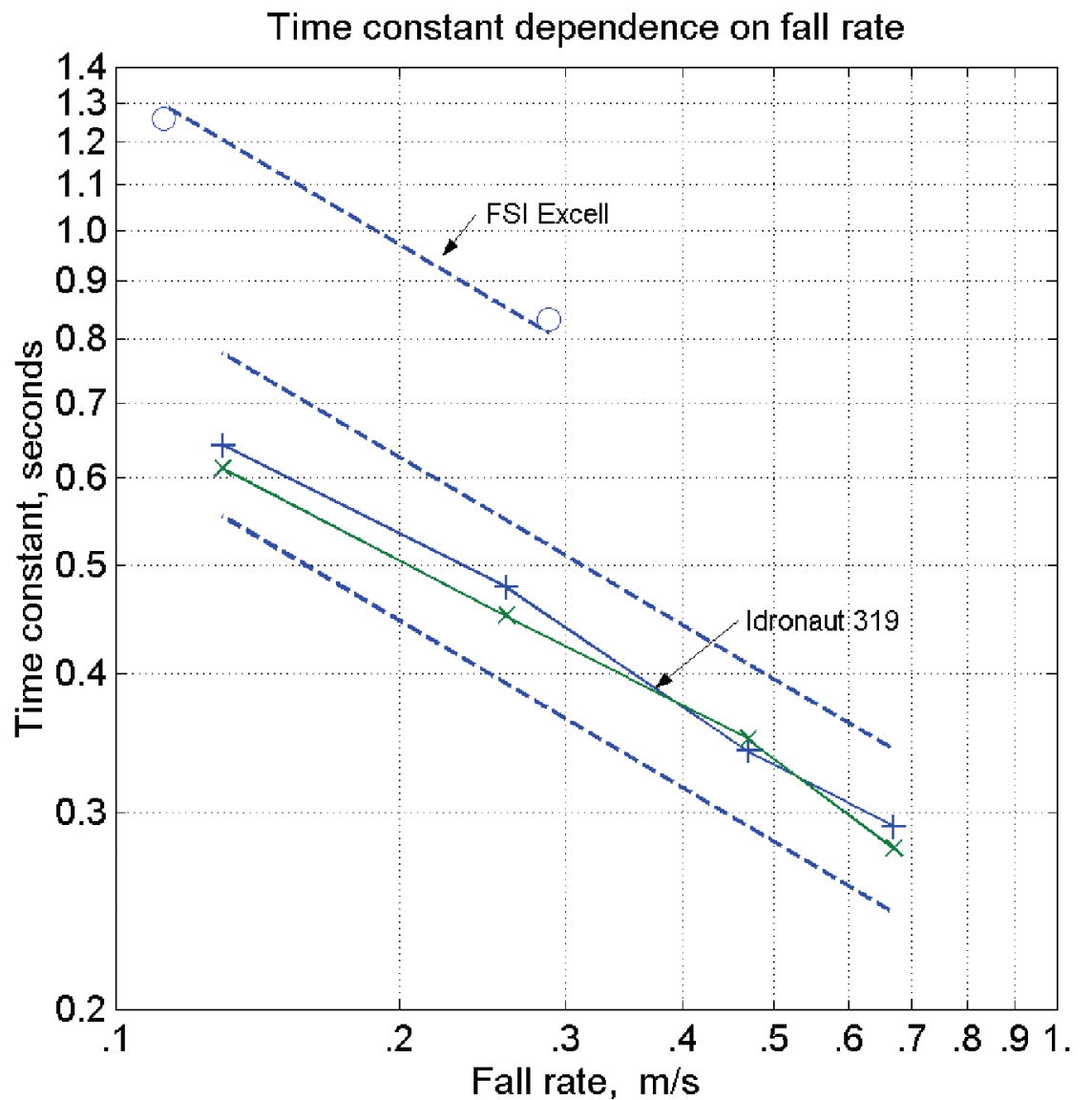

Figure 10. The dependence of estimated thermometer time constant on fall rate for the FSI Excell $(\bigcirc)$ and the Idronaut 319 CTDs $(+, x)$. The Idronaut has two temperature probes with very similar time constants. All dashed lines have a slope of $w^{-1 / 2}$.

\section{Summary}

As presented above, the double-diffusive interface tank has been found to be particularly useful for a priori characterization of the dynamic response of sensors deployed on autonomous instruments where the necessity for on-board data reduction precludes post-hoc correction of the data. Linear and nonlinear fitting procedures were developed to estimate the response time of sensors for ideal and finite thickness steps. Runs at different fall rates are consistent with a $w^{-1 / 2}$ scaling for thermometer time constants, which suggests that some CTDs could benefit from speed-dependent lag correction algorithms. The conductivity-temperature plot was found to be an efficient diagnostic for identifying sensor lag, response time, and thermal mass effects. We have also used the tank for 
performance testing of profiling floats and studies of the relative mixing rates of dissolved salts and injected tracers. Characterization of the dynamic response of various CTDs, as well as optical, acoustic and microstructure sensors to the sharp temperature/salinity interface is planned.

Acknowledgments. WHOI Summer Student Fellows Mark Szigety and David Stuebe assisted with the tank development. Rosanna Fucile prepared Figure 1. Rolf Lueck provided a valuable critique of an earlier manuscript and alerted us to the advantages of the bilinear filter. Coding for the Levenberg-Marquardt regression technique originally due to Lindsey Pender of CSIRO, Hobart, was adapted to this application. All of the authors owe a great debt to Nick Fofonoff, who served as mentor and guide to us as well as several generations of CTD users at WHOI and elsewhere. He was a pioneer in the use of modern CTD data and we are pleased to dedicate this manuscript to his memory. This research was supported by the National Science Foundation, grants OCE-97-11869 and OCE-02-40956, NOAA CORC grant 154368 and a WHOI Mellon Technical Staff Award. This is WHOI contribution number 11320.

\section{APPENDIX}

\section{Filter response at slow sample rates}

The recursive filter weights calculated using relation 3.8 from Bendat and Piersol (1971) do not correctly model the behavior of a single pole filter as the sampling period approaches the sensor response time. It is possible to derive a different expression for the filter weight that will yield a modest improvement in the performance of the standard recursive filter, Eq. (7), for short sampling periods. That is, the relation $a=1 /(1+\Delta / \tau)$ provides more phase shift than the classic exponential expression Eq. (8) for $\Delta \rightarrow \tau$. However, neither of these traditional recursive filters perform as well in this limit as the "bilinear" filter suggested by Mudge and Lueck (1994). To illustrate this point we have plotted the amplitude response and phase shift for these three approaches for comparison with the ideal single-pole filter response in Figures A.1.a,b $(\Delta \ll \tau)$ and A.1.c,d $(\Delta \sim \tau)$.

Plots of the amplitude squared and phase for the single pole temperature probe model and the recursive conductivity filter using the exponential and algebraic expressions for $a$ are shown in Figure A1a-d. The lower panels $(\mathrm{c}-\mathrm{d})$ are for the case of a sample interval $(\Delta=0.04 \mathrm{~s})$ that is short compared to the sensor response time $(\tau=0.5 \mathrm{~s}, \Delta \ll \tau)$. For this situation, the three models exhibit amplitude and phase behavior similar to the ideal single pole filter. The upper panels $(\mathrm{a}-\mathrm{b})$ are for a situation where the sample interval $(\Delta=1.0 \mathrm{~s})$ is comparable to the sensor lag $(\tau=0.5$ s, i.e., $\Delta \cong \tau)$. The simple recursive filters over- or under-estimate the amplitude and more importantly underestimate the phase with increasing frequency, whereas the bilinear filter provides a better estimate of both amplitude and phase for frequencies approaching the Nyquist. Thus, while the simple filters perform well enough when the sampling interval is short, the bilinear filter is superior when the sample interval is comparable to the sensor response time. 

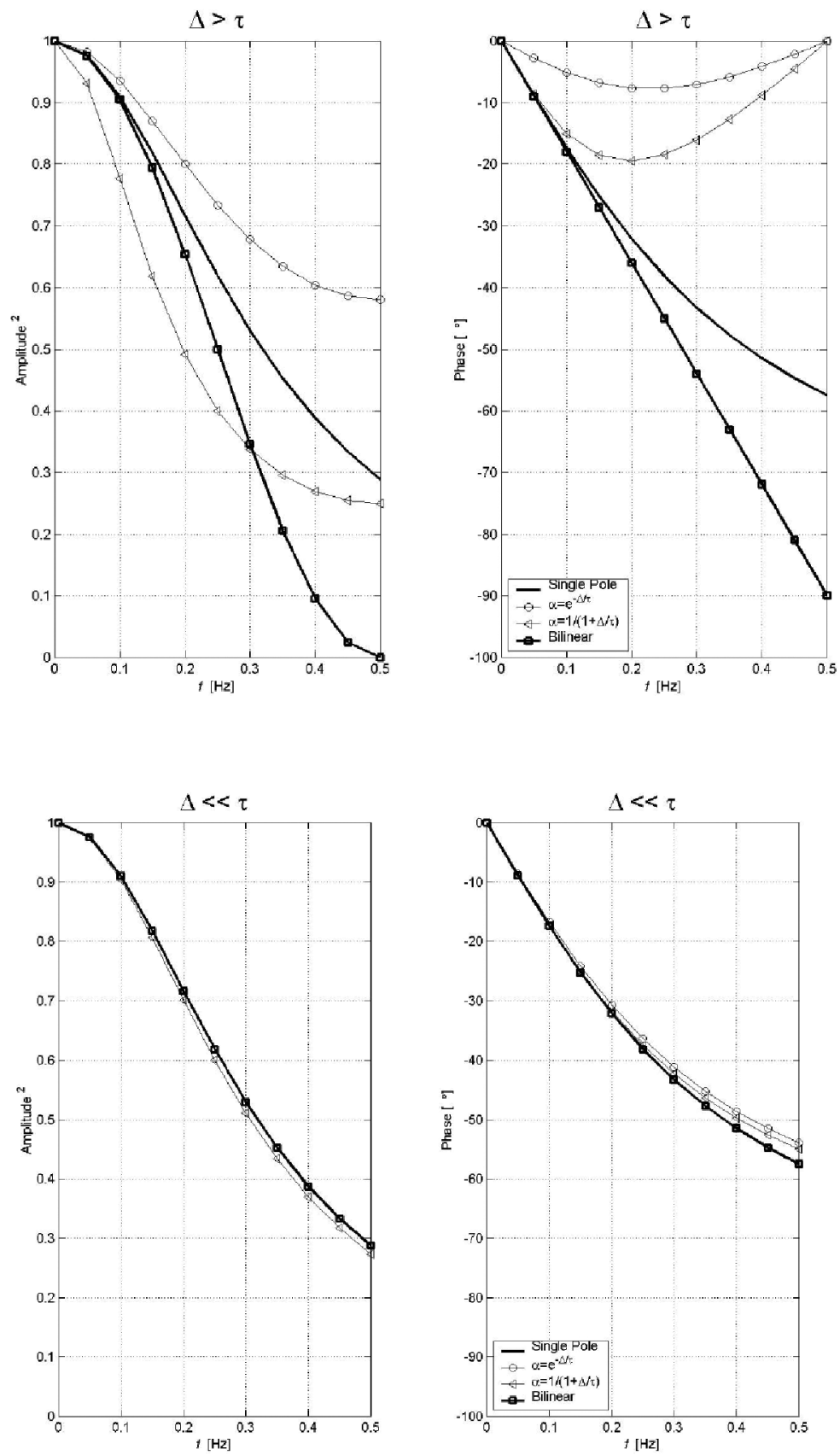

Figure A1. (a-b) (top panels) Evaluation of the amplitude squared and the phase for recursive and bilinear filters given in Eqs. (7) and (9), compared with ideal single pole response. This represents the case where the sample interval $(\Delta)$ and lag $(\tau)$ are approximately equal. (c-d) (bottom panels) Evaluation of Eq. 4 for the square of amplitude response and Eq. 3 for the phase. This represents the case where the instrument sample interval $(\Delta)$ is much smaller than the lag $(\tau)$. 


\section{REFERENCES}

Bendat, J. S. and A. G. Piersol. 1971. Random Data: Analysis and Measurement Procedures, Wiley-Interscience, NY, 407 pp.

Davis, R. E., D. C. Webb, L. A. Regier and J. Dufour. 1992. The autonomous Lagrangian circulation explorer. J. Atmos. Oceanic Tech., 9, 264-285.

Fofonoff, N. P., S. P. Hayes and R. C. Millard. 1974. WHOI/Brown CTD microprofiler: methods of calibration and data handling. Woods Hole Oceanographic Institution Technical Report, 66, 74-89.

Fofonoff, N. P. and R. C. Millard, Jr. 1983. Algorithms for computation of fundamental properties of seawater. UNESCO Technical Papers in Marine Science, 44. Unesco, Paris.

Fozdar, F. M., G. J. Parker and J. Imberger. 1985. Matching temperature and conductivity sensor response characteristics. J. Phys. Oceanogr., 15, 1557-1569.

Giles, A. B. and T. J. McDougall. 1986. Two methods for the reduction of salinity spiking of CTDs. Deep-Sea Res., 33, 1253-1274.

Gregg, M. C. and W. C. Hess. 1985. Dynamic response calibration of Sea-Bird temperature and conductivity probes. J. Atmos. Ocean Tech., 2, 304-313.

Gregg, M. C. and T. B. Meagher. 1980. The dynamic response of glass-rod thermistors. J. Geophys. Res., 85, 2779-2786.

Gregg, M. C., T. B. Meagher, E. E. Aagaard and W. C. Hess. 1981. A salt-stratified tank for measuring the dynamic response of conductivity probes. IEEE J. Oceanic Eng., OE-6 (4), 113-118.

Gregg, M. C., J. C. Schedvin, W. C. Hess and T. B. Meagher. 1982. Dynamic response calibration of the Neil Brown conductivity cell. J. Phys. Oceanogr., 12, 720-742.

Horne, E. P. W. and J. M. Toole. 1980. Sensor response mismatches and lag correction techniques for temperature-salinity profilers. J. Phys. Oceanogr., 10, 1122-1130.

Linden, P. F. and T. G. F. Shirtcliffe. 1978. The diffusive interface in double-diffusive convection. J. Fluid Mech., 87, 417-432.

Lueck, R. 1990. Thermal inertia of conductivity cells: theory. J. Atmos. Oceanic Tech., 7, 741-755.

Lueck, R., O. Hertzman and T. Osborn. 1977. The spectral response of thermistors. Deep-Sea Res., 24, 951-970.

Lueck, R. and J. Picklo. 1990. Thermal inertia of conductivity cells: observations with a Sea-Bird cell. J. Atmos. Oceanic Tech., 7, 756-768.

McDougall, T. J. 1981. Double-diffusive convection with a nonlinear equation of state. II. Laboratory experiments and their interpretation. Prog. Oceanogr., 10, 91-121.

Middleton, J. H. and T. D. Foster. 1980. Fine structure in the halocline. J. Geophys. Res., 85, $1118-1122$.

Millard, R. C., Jr. 1982. CTD calibration and data processing techniques at WHOI using the 1978 practical salinity scale. Proceedings of the International STD Conference and Workshop, La Jolla, CA, 8-11 Feb. 1982. Marine Technology Society 19 pp.

Morison, J., R. Andersen, N. Larson, E. D’Asaro and T. Boyd. 1994. The correction for thermal-lag effects in Sea-Bird CTD data. J. Atmos. Oceanic Tech., 11, 1151-1164.

Mudge, T. D. and R. G. Lueck. 1994. Digital signal processing to enhance oceanographic observations. J. Atmos. Oceanic Tech., 11, 825-836.

Muench, R. D., H. J. S. Fernando and G. R. Stegan. 1990. Temperature and salinity staircases in the northwestern Weddell Sea. J. Phys. Oceanogr., 20, 295-306.

Neal, V. T., S. Neshyba and W. Denner. 1969. Thermal stratification in the Arctic Ocean. Science, $166,373-374$.

Ochoa, J. 1989. A practical determination of CTD platinum resistance thermometer response time, and its use to correct salinity bias and spikes. Deep-Sea Res., 36, 139-148. 
Press, W. H., B. P. Flannery, S. A. Teukolshy and W. T. Vetterling. 1986. Numerical Recipes, Cambridge University Press, Cambridge, U. K. 818 pp.

Scarlet, R. I. 1975. A data processing method for salinity, temperature, depth profiles. Deep-Sea Res., 22, 509-515.

Schmitt, R. W. 1979. Flux measurements on salt fingers at an interface. J. Mar. Res., 37, 419-436.

— 1994. Double diffusion in oceanography. Ann. Rev. Fluid Mech., 26, 255-285.

Shirtcliffe, T. G. L. 1967. Thermosolutal convection: observation of an overstable mode. Nature, 213, 489-490.

Stern, M. E. 1960. The 'salt fountain' and thermohaline convection. Tellus, 12, 172-175.

Stern, M. E. and J. S. Turner. 1969. Salt fingers and convecting layers. Deep-Sea Res., 16, 497-511. Tabor, H. 1981. Solar ponds. Solar Energy, 27, 181-194.

Topham, David R. and Ronald G. Perkin. 1988. CTD sensor characteristics and their matching for salinity calculations. J. Ocean Eng., 13, 107-117.

Turner, J. S. 1965. The coupled turbulent transports of salt and heat across a sharp density interface. Int. J. Heat Mass Trans., 8, 759-767.

1968. The behavior of a stable salinity gradient heated from below. J. Fluid Mech., 33, 183-200.

Turner, J. S. and H. Stommel. 1964. A new case of convection in the presence of combined vertical salinity and temperature gradients, Proceedings of the National Academy of Sciences, 52, 49-53. Unesco. 1981. Background papers and supporting data on the Practical Salinity Scale 1978. Tech. Papers in Mar. Sci., 37, Unesco, Paris.

Veronis, G. 1968. Effect of a stabilizing gradient of solute on thermal convection. J. Fluid Mech., 34, $\underline{315-336 .}$

Received 28 June, 2004; revised: 16 December, 2004. 